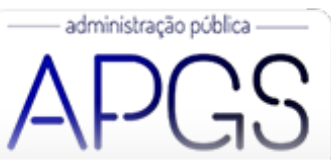

Administração Pública e Gestão Social ISSN: 2175-5787

apgs@ufv.br

Universidade Federal de Viçosa

Brasil

\title{
Análise de Evidências e Causas do Efeito Flypaper e da llusão Fiscal nos Estados e Municípios Brasileiros
}

Azevedo Pansani, Daniel; Marques Serrano, André Luiz; Oliveira Gomes Ferreira, Lucas

Análise de Evidências e Causas do Efeito Flypaper e da llusão Fiscal nos Estados e Municípios Brasileiros

Administração Pública e Gestão Social, vol. 12, núm. 3, 2020

Universidade Federal de Viçosa, Brasil

Disponible en: http://www.redalyc.org/articulo.oa?id=351563312017

Esta obra está bajo una Licencia Creative Commons Atribución-NoComercial-SinDerivar 3.0 Internacional. 


\title{
Análise de Evidências e Causas do Efeito Flypaper e da Ilusão Fiscal nos Estados e Municípios Brasileiros
}

\author{
Analysis of Evidences and Causes of the Flypaper Effect and Fiscal Illusion in the Brazilian States and Municipalities \\ Análisis de Evidencias y Causas del Efecto Flypaper y de la Ilusión Fiscal en los Estados y Municipios Brasileños
}

Daniel Azevedo Pansani

Universidade de Brasilia - UnB, Brasil

Redalyc: http://www.redalyc.org/articulo.oa?

danielpansani@gmail.com

André Luiz Marques Serrano

Universidade de Brasilia - UnB, Brasil

andrelms.unb@gmail.com

Lucas Oliveira Gomes Ferreira

Universidade de Brasilia - UnB, Brasil

lucasogf@gmail.com id $=351563312017$

Recepción: 18 Marzo 2019

Aprobación: 03 Noviembre 2019

Publicación: 01 Julio 2020

\section{Resumo:}

A teoria da ilusão fiscal refere-se ao fenômeno pelo qual os governantes criam distorções sobre a realidade fiscal nos contribuintes, dificultando a percepção sobre o preço dos serviços públicos, por meio de mecanismos como utilização de transferências governamentais para aumento de gastos ao invés de redução de impostos (efeito flypaper). A pesquisa objetiva analisar as evidências de ilusão fiscal no país, a partir dos estudos de Araújo (2014) e Araújo e Siqueira (2016), utilizando o modelo do eleitor mediano. O presente trabalho utiliza dados de 2004 a 2015 por Unidade da Federação. Com a utilização de modelo de efeitos fixos de regressão com dados em painel e com a utilização de erros robustos, são encontradas evidências do efeito flypaper e, parcialmente, da ilusão causada pela complexidade de receita.

PALAVRAS-CHAVE: Ilusão fiscal, Efeito fypaper, Estrutura tributária, Estados e municípios brasileiros.

\section{Abstract:}

The fiscal illusion theory refers to the phenomenon by which rulers create distortions about taxpayers' fiscal reality, making it difficult to perceive the price of public services, through mechanisms such as use of government transfers to increase spending rather than tax reduction (flypaper effect). The research aimed to analyze the evidence of fiscal illusion in Brazil, based on the studies of Araújo (2014) and Araújo and Siqueira (2016) through the median voter model. The present paper uses data from 2004 to 2015 for Brazilian states. With the use of a fixed-regression model with panel data and the use of robust errors, evidence is found of the flypaper effect and partly of the illusion caused by the complexity of revenue.

KEYWORDS: Fiscal illusion, Flypaper Effect, Tax structure, States and municipalities.

\section{RESUMEN:}

La teoría de la ilusión fiscal se refiere al fenómeno por el cual los gobernantes crean distorsiones sobre la realidad fiscal en los contribuyentes, dificultando la percepción en cuanto al precio de los servicios públicos, por medio de mecanismos como utilización de transferencias gubernamentales para aumentar los gastos en lugar de reducción de impuestos (efecto flypaper). La investigación objetiva analizar las evidencias de ilusión fiscal en Brasil, a partir de los estudios de Araújo (2014) y Araújo y Siqueira (2016), utilizando el modelo del elector mediano. El presente estudio utiliza datos de 2004 a 2015 por estados Brasileños, con modelo de efectos fijos de regresión con datos en panel y con errores robustos, se encuentran evidencias del efecto flypaper y, en parte, de la ilusión causada por la complejidad de los ingresos.

Palabras ClaVe: Ilusión fiscal, Efecto Flypaper, Estructura tributaria, Estados y municipios brasileños. 


\section{INTRODUÇÃO}

O conceito de descentralização fiscal visa ajustar os princípios do desenvolvimento econômico regional com base no governo subnacional parcialmente financiado pelo orçamento nacional (Kusuma, 2017). De acordo com a teoria do federalismo fiscal, uma vez que é papel do Estado corrigir falhas de mercado, os entes nacionais ofertam, indiretamente, bens e serviços públicos mais adequados às características locais, por meio de uma espécie de contrato entre governo central e governos subnacionais, através de repasses (transferências) (Giambiagi \& Além, 2016). Outra característica dessas transferências é a de reduzir os desequilíbrios fiscais existentes entre os diversos entes subnacionais (Oates, 1999).

O termo flypaper, caracterizado pela ilusão causada por transferências intergovernamentais, sobretudo pelas não condicionadas (lump sum), na medida em que gera uma expansão do gasto maior do que a causada pelo aumento da renda dos contribuintes, foi atribuído por Courant, Gramlich e Rubinfeld (1978) e Marshal (1989) à afirmação de Arthur Okun de que "o dinheiro gruda onde bate" (tradução livre de "Money sticks where it hits"). Ou seja, o dinheiro do setor privado tende a nele permanecer, enquanto que o dinheiro no setor público tende a ser gasto no setor público, ao invés de ser "repartido" entre os cidadãos. O conceito está relacionado ao entendimento de que os agentes políticos maximizam o orçamento, escondendo a natureza fixa das receitas advindas das transferências. Ao invés de os recursos serem devolvidos aos contribuintes, por meio de redução de impostos, por exemplo, os agentes públicos lançam mão da disponibilidade dos recursos para aumentar o orçamento, causando uma percepção de redução no preço do imposto para financiar programas de gastos locais (Oates, 1988; Dollery \& Worthington, 1996).

Nessa situação os contribuintes não seriam capazes de diferenciar as receitas geradas por meio de impostos daquelas recebidas por transferências ou subvenções, permitindo que os governantes optem por aumentar o gasto público ao invés de aumentar a renda do cidadão, por meio da redução de impostos. Nesse sentido, o efeito flypaper gera distorção na percepção do contribuinte em relação a sua participação no custo de oportunidade do gasto público, ou seja, o contribuinte acredita pagar um preço menor pelos bens e serviços ofertados pelo governo (Mourão, 2007, 2008; Dollery \& Worthington, 1996).

Qualquer forma de ilusão depende do ambiente fiscal para ser aplicada. Sobretudo a partir da Constituição Federal de 1988, o federalismo fiscal adotado no Brasil, por exemplo, ao mesmo tempo em que concede aos entes subnacionais (estados e municípios) maior autonomia administrativa e financeira, facilita a utilização de instrumentos ilusórios. Mesmo com a existência de mecanismos de controle, a descentralização característica do federalismo abre espaço para comportamentos fiscais irresponsáveis por parte dos administradores de recursos, seja nos estados ou nos municípios (Carvalho, Oliveira, \& Carvalho, 2009; Cossío, 1998; Veloso, 2008; Nascimento, 2010; Massardi \& Abrantes, 2016; Morais \& Bonifácio, 2016).

No geral, os estudos realizados com enfoque no Brasil que encontram evidências de ilusão fiscal o fazem com base em dados municipais (Cossio \& Carvalho, 2001; Guedes \& Gasparini, 2007; Varela, Martins, \& Fávero, 2010; Mattos, Rocha, \& Arvate, 2011; Sakurai, 2013; Araújo; 2014; Araújo \& Siqueira, 2016; Diniz, Lima, \& Martins, 2017). Silva e Siqueira (2013) apresentam-se como exceção, uma vez que analisaram o ambiente federal de ilusão fiscal sob a hipótese de Mill. Assim, o impacto relevante da tributação estadual sobre os contribuintes não é adicionado em qualquer dos estudos mencionados, representando uma lacuna sobre evidências de ilusão fiscal no Brasil. Assim, o objetivo do presente trabalho é analisar as evidências de ilusão fiscal no Brasil sob os aspectos do efeito flypaper e da ilusão causada pela complexidade da estrutura tributária, com base em dados agregados de estados e municípios.

A relevância de se estudar ilusão fiscal no Brasil se dá com base em indicadores fiscais como o crescimento do gasto público e da carga tributária após o período de redemocratização, pois a teoria da ilusão fiscal representa o fenômeno pelo qual os governantes criam distorções sobre a realidade fiscal nos contribuintes, dificultando a percepção quanto ao preço dos serviços públicos, por meio de mecanismos como sistema tributário complexo (complexidade da receita), pulverização de tributos (concentração) ou prevalência de 
tributação indireta (hipótese de Mill), utilização de transferências governamentais para aumento de gastos ao invés de redução de impostos (efeito flypaper), diferimento de gastos por dívida ou déficits.

Portanto, a contribuição do trabalho consiste em fornecer um diagnóstico do cenário tributário brasileiro por meio da análise de evidências de ilusão fiscal e efeito flypaper no Brasil, possibilitando inclusive guiar as autoridades legislativas e tributárias quanto aos aspectos tributários discutidos no processo legislativo.

Com base na teoria do eleitor mediano, os planos de governo e, consequentemente, os gastos públicos, deveriam estar relacionados às preferências do eleitor de renda mediana. Entretanto, há diversas evidências na literatura de que os gastos públicos refletem mais a vontade dos representantes do que dos representados, pois para que ocorresse o contrário, deveria haver uma percepção clara dos custos e benefícios dos serviços públicos. É exatamente na questão da distorção de percepção do eleitor que se encaixa a teoria da ilusão fiscal. As evidências identificadas demonstram como realmente a estrutura tributária brasileira é, pois quanto mais simples a estrutura tributária, menor o incentivo para aumentar do gasto público. Adicionalmente, quanto maior a representatividade de tributos indiretos, maior a dificuldade de percepção da carga tributária por parte dos contribuintes e, consequentemente, mais difícil é a percepção dos contribuintes quanto ao preço dos serviços públicos.

O estudo é composto por cinco capítulos, incluindo esta introdução. O capítulo 2 diz respeito à revisão da literatura acerca da ilusão fiscal e seus tipos. $\mathrm{O}$ capítulo 3 , especificamente, trata da metodologia, das variáveis e do modelo econométrico desenvolvido. O capítulo 4 apresenta os resultados obtidos, além de apresentar uma análise dos dados utilizados com base na teoria. Por fim, no capítulo 5 são apresentadas as considerações finais.

\section{REVISÃO DA LITERATURA}

Ainda que só a partir de 1979 tenha surgido o termo efeito flypaper, estudos anteriores, acerca de outros tipos de ilusão fiscal, já incluíam as transferências intergovernamentais e demonstravam impactos significativos no nível dos gastos públicos (Oates, 1975; Wagner, 1976; Munley \& Greene, 1978).

Courant, Gramlich e Rubinfeld (1978) e Oates (1979) concluíram que as transferências não condicionadas reduzem a percepção do preço médio dos bens públicos e os eleitores baseiam suas decisões de alocação sobre esse preço, em vez de basearem no preço marginal real. Para Winer (1983) e Logan (1986), as transferências fazem com que os eleitores percebam que sua carga tributária é transferida para outras jurisdições. Ambas as linhas de conclusão, seja a de Courant, Gramlich e Rubinfeld (1978) e Oates (1979), seja a de Winer (1983) e Logan (1986), apontam que as transferências ou subvenções reduzem o custo marginal percebido do bem público, possibilitando o aumento da despesa pública (Dollery \& Worthington, 1996).

Oates (1988), mesmo afirmando que o efeito flypaper era uma das possibilidades de ilusão fiscal, já indicava que não seria necessário qualquer tipo de ilusão fiscal para gerar o efeito flypaper. Romer e Rosenthal (1979), por exemplo, mostram que nos locais em que é estabelecido um modelo de controle orçamentário (agenda control model), há grande possibilidade de gastos públicos excessivos. Os responsáveis pelo orçamento se aproveitariam de alternativas orçamentárias pouco atrativas (maiores gastos públicos), sendo que a mais atrativa do ponto de vista do eleitorado ainda poderia ser considerada uma reversão da situação prejudicial da menos atrativa, o que causaria uma sensação de reversão do "pior orçamento". Assim, Oates (1988) defende a necessidade de mais evidências empíricas do efeito flypaper.

Os resultados de Logan (1986) e Hammes e Wills (1987) indicam uma correlação negativa entre o nível dos gastos em entes subnacionais receptores de transferência e o nível de gastos nos entes concedentes, provando que houve mudança do preço dos impostos na direção oposta dos gastos, oferecendo suporte à hipótese de ilusão fiscal. 
Grossman (1990) e Marshal (1991) consideram que a questão do efeito flypaper está relacionada também ao nível de governo em que ocorre. Nesse entendimento, as transferências federais, por exemplo, seriam mais indiretas do que as estaduais, em termos de financiamento dos governos municipais ou locais. Grossman (1990) encontrou evidências de que quanto mais indireta é a relação entre o ente transferidor e o recebedor, maior o estímulo para o aumento no nível de despesas locais (Grossman, 1990). Dollery e Worthington (1995a, 1995b) avaliam que o gasto público líquido das subvenções e transferências na Austrália também apresentam evidências empíricas do efeito flypaper.

Inman (2008) apontou que no ano de seu trabalho já havia mais de 3.500 pesquisas que tentavam explicar o efeito flypaper, demonstrando a quantidade representativa de pesquisas que investigam o fenômeno. $\mathrm{O}$ autor classifica, inicialmente, o efeito flypaper como uma anomalia, testando três explicações possíveis. Em primeiro lugar, seria um problema de dados, haja vista que as pesquisas classificam, incorretamente, as transferências condicionadas como lump sum. O segundo ponto diz respeito a problemas econométricos, pois, como afirma o autor, há especificação incorreta dos modelos, que omitem variáveis relevantes. Em terceiro lugar, trata-se de um problema de especificação: O eleitor mediano não consegue observar a transferência não condicionada, ou, quando observa, interpreta equivocadamente os efeitos no preço médio dos bens e serviços públicos. Por fim, afirma que nenhuma das três hipóteses é suficientemente explicada por evidências empíricas (Inman, 2008).

Yu, Wang e Tian (2016) não encontraram evidências do efeito flypaper na China, especificamente avaliando dados educacionais. Cabe destacar, no entanto, que o país não possui um sistema de voto, não sendo possível a aplicação do modelo do eleitor mediano no trabalho. Por não evidenciar o efeito flypaper, o trabalho não necessariamente ratifica a equivalência entre os efeitos das transferências e da renda nos gastos públicos. O estudo, na realidade, encontra o que os autores denominam de "anti-efeito flypaper". Uma explicação é que as decisões políticas feitas pelos governantes locais (subnacionais) se baseiam no próprio interesse dos representantes.

Por meio da utilização do modelo burocrático, em que os aspectos políticos são mais presentes do que no modelo do eleitor mediano, Kusuma (2017) encontrou evidências de efeito flypaper após a implementação de descentralização fiscal na província de Java Oriental, na Indonésia. Apesar de serem encontrados na literatura internacional trabalhos sobre o efeito flypaper desde a década de 1970, no Brasil os trabalhos que tratam especificamente do assunto se concentram no século XXI.

Embora não tratem especificamente do termo ilusão fiscal, Cossío e Carvalho (2001) constataram a existência do efeito flypaper nas finanças municipais do Brasil, uma vez que, com dados de 1996, as transferências constitucionais para os municípios provocaram expansão de gastos públicos significativamente maior do que a identificada pelo aumento da renda per capita dos contribuintes. Complementarmente, evidenciou-se que as regiões Norte e Nordeste do Brasil apresentam os municípios mais dependentes das transferências, devido à menor base de tributação e menor capacidade de explorar a já reduzida base.

Guedes e Gasparini (2007), ao analisarem os efeitos da descentralização fiscal no Brasil e o tamanho do governo, encontraram evidências de que a maior parte dos gastos locais é financiada por transferências intergovernamentais. Os dados utilizados no trabalho consideraram o agrupamento de informações municipais por estado, no período de 1998 a 2001, por meio de um modelo de dados em painel com efeitos fixos.

Com base em dados de municípios do Estado de São Paulo para o ano de 2008, Varela, Martins e Fávero (2010) mediram a eficiência dos gastos dos recursos públicos nas ações de atenção básica à saúde e encontraram evidências de que seria possível aumentar a eficiência dos gastos sem a necessidade de novas dotações. Demonstraram ainda que as transferências não condicionadas geram um efeito negativo no escore de eficiência obtida, o que corrobora a hipótese do efeito flypaper, enquanto que os repasses de recursos específicos do Sistema Único de Saúde (SUS), ou seja, condicionados, geraram efeito positivo sobre o escore. 
A pesquisa de Mattos, Rocha e Arvate (2011) propõe uma reinterpretação do efeito flypaper, uma vez que a análise ocorre considerando-se o lado da eficiência da receita (coleta de impostos) e não pelo lado da despesa, comumente utilizado. Para os autores, as transferências mais altas podem induzir à menor eficiência na arrecadação dos entes subnacionais. A partir de dados municipais de 2004, Mattos, Rocha e Arvate (2011) demonstram que o efeito das transferências sobre a eficiência é negativo, oposto ao exercido pela renda, evidência de ocorrência do efeito flypaper.

Sakurai (2013) analisa os efeitos das transferências governamentais sobre os gastos lançando mão de uma amostra de 4.846 municípios, com dados fiscais (despesas e transferências), dados relativos à renda e quantidade de jovens e idosos da população, para o período compreendido entre 1989 e 2005 . Foram encontrados resultados que sugerem a existência do efeito flypaper em âmbito municipal. O autor aponta que o resultado é reforçado ao se considerar que cerca de $70 \%$ dos municípios possuem população inferior a 20 mil habitantes e que estes possuem base tributária própria limitada, sendo as transferências a única fonte estável de receita (Sakurai, 2013).

Araújo (2014) e Araújo e Siqueira (2016) estudaram a ilusão fiscal no Brasil através de dados de 2010 dos municípios brasileiros, estimando uma função de demanda com base no modelo do eleitor mediano para identificar se a inclusão de variáveis de ilusão fiscal no modelo gera os efeitos esperados no nível do gasto público. As variáveis de ilusão fiscal utilizadas se referem às transferências não condicionadas, de modo a verificar a existência do efeito flypaper, e uma variável de simplicidade fiscal, que relaciona o nível de complexidade tributária medida pelo Índice de Herfindahl-Hirschman (IHH) a um índice de visibilidade tributária, representada pela razão entre impostos diretos e indiretos. Os resultados atingidos corroboram com a existência de ilusão fiscal no Brasil, tanto manifestada pelo efeito flypaper quanto pelo nível de simplicidade fiscal (Araújo, 2014; Araújo \& Siqueira, 2016).

Por fim, Diniz, Lima e Martins (2017) identificaram que os municípios com maiores receitas próprias são mais eficientes, enquanto os que recebem mais recursos do que enviam para o Fundo de Manutenção e Desenvolvimento da Educação Básica e de Valorização dos Profissionais da Educação (Fundeb) são menos eficientes, confirmando a existência do efeito flypaper nos municípios paraibanos. Conforme verificado, os trabalhos realizados no Brasil, em geral, possuem base de dados municipal, procurando evidenciar o efeito flypaper em nível local. Uma vez que as transferências governamentais efetuadas da União para estados não são consideradas em nenhuma das pesquisas, vislumbra-se uma lacuna para analisar a ocorrência do efeito flypaper com dados agregados dos municípios e estados, já que os recursos recebidos pelo estado também são utilizados no fornecimento de bens e serviços ao cidadão.

\section{METODOLOGIA}

Por meio de dados de 2004 a 2015 consolidados por Unidade da Federação, o modelo utilizado na presente pesquisa baseia-se em Araújo (2014) e Araújo e Siqueira (2016), construído a partir teoria da escolha pública, desenvolvida por Borcherding e Deacon (1972) e Bergstrom e Goodman (1973). O período da pesquisa iniciou-se em 2004 em função da disponibilidade dos dados nos sistemas Finanças do Brasil (Finbra) e Sistema de Informações Contábeis e Fiscais do Setor Público Brasileiro (Siconfi), os quais possuem rubricas específicas que possibilitam a classificação dos tributos diretos e indiretos. O Instituto Brasileiro de Geografia e Estatística (IBGE) fornece dados de renda mediana somente até o ano de 2015, o que justifica o período da pesquisa somente até esse ano, pois essa variável é essencial para a verificação do efeito flypaper (Quadro 1). Gemmel, Morrissey e Pinar (2002) iniciam a modelagem a partir da seguinte definição:

$$
E \equiv C G
$$


Em que E representa o gasto total do governo, $G$ é a produção total de serviços públicos e $C$ é o custo unitário de G. O gasto total do governo está sujeito à seguinte restrição orçamentária.

$$
C G \leq t B
$$

Em 2, representa todos os tributos e diz respeito à alíquota de. A produção total de bens e serviços públicos, de acordo com Bergstrom e Goodman (1973) pode ser descrita pela equação:

$$
G=g_{i} N^{\eta}
$$

Onde é o serviço demandado pelo contribuinte mediano i, $\mathrm{N}$ é a população e $\eta$ representa o grau de publicidade de G. O gasto per capita pode ser definido como. Aplicando essa igualdade em 1 e 3, chega-se à seguinte equação:

$$
e_{i}=C g_{i} N^{\eta-1}
$$

Gemmell, Morrissey e Pinar (2002) apontam que deriva-se da equação de maximização de utilidade abaixo:

$$
g_{i}=\alpha y_{i}^{\beta_{1}} P_{g i}^{\beta_{2}} z_{i}^{\beta_{3}}
$$

Em que, e são renda disponível, preço do imposto e vetor de outras variáveis explicativas, respectivamente, e os são elasticidades.

Araújo (2014) e Araújo e Siqueira (2016) descrevem a renda disponível , conforme equação 6.

$$
y_{i}=t b_{i}+x
$$

Em que é a base tributária do eleitor mediano e é quantidade de consumo do bem privado. Assim, por meio da aplicação de 2 e 3 em 6, é possível chegar à seguinte equação:

$$
y_{i}=t b_{i}+x
$$

Araújo (2014) ainda inclui a equação da taxa de substituição entre o consumo privado e a oferta de bens e serviços públicos , representada em 7 .

$$
y_{i}=\frac{C g_{i} N^{\eta}}{B} b_{i}+x
$$

Considerando que é a base tributária média, indica a representatividade da base tributária do eleitor mediano (tax share). O preço do imposto para o eleitor mediano é dado em função da tax share, da população, do custo unitário do bem público e do grau de publicidade do bem ou serviço público.

Retomando as equações 3, 4 e 5, colocando em função do gasto total, e multiplicando por , é obtida uma função de estimação para o gasto público per capita (demanda por bens públicos locais), conforme equação 9. De acordo com Araújo (2014), a equação é amplamente utilizada para analisar a elasticidade do preço da demanda e o grau de publicidade dos bens e serviços (efeito congestionamento).

$$
e_{i}=P_{g_{i}} g_{i} N^{\eta-1}=\alpha y_{i}^{\beta_{1}} P_{g i}^{\beta_{2}+1} N^{\eta-1} z_{i}^{\beta_{3}}
$$

Considerando a equação 8 em 9, é obtida a igualdade 10: 


$$
e_{i}=\alpha y_{i}^{\beta_{1}}\left[\frac{b_{i}}{b} N^{\eta-1} C\right]^{\beta_{2}+1} N^{\eta-1} z_{i}^{\beta_{3}}
$$

Ao considerar em 8 que o custo unitário é igual a 1, é obtida a seguinte equação para o preço do tributo:

$$
P_{g_{i}}=\frac{b_{i}}{b} N^{\eta-1}
$$

Haja vista que o presente trabalho assume que o contribuinte (eleitor mediano) está sujeito à ilusão fiscal, deve ser incluído um fator de percepção no preço do imposto. Assim, como características da estrutura fiscal que indicam a existência de ilusão foram consideradas as transferências não condicionadas recebidas e a simplicidade fiscal. Dessa forma, define-se o parâmetro em 12:

$$
\Pi_{i}=T C_{i}^{\pi} S F I S_{i}^{\pi}
$$

Em que representa as transferências correntes e o índice de simplicidade fiscal, ambas características da estrutura fiscal local, percebidas pelo índivíduo . O detalhamento das variáveis é apresentado no item seguinte. Assim, define-se como o preço do tributo percebido pelo contribuinte mediano.

$$
\hat{P}_{g_{i}}=\Pi_{i} P_{g_{i}}
$$

A presente pesquisa amplia o alcance da base de avaliação dos trabalhos de Araújo (2014) e Araújo e

\begin{tabular}{|c|c|c|c|c|c|}
\hline Variável & Sigla & Breve descrição & $\begin{array}{c}\text { Fonte de } \\
\text { Coleta }\end{array}$ & $\begin{array}{c}\text { Unidade de } \\
\text { Medida }\end{array}$ & $\begin{array}{c}\text { Sinal } \\
\text { Esperado }\end{array}$ \\
\hline $\begin{array}{l}\text { Gasto público per capita } \\
\text { (VD) }\end{array}$ & $\mathrm{DC}$ & Representado pela despesa corrente, refletindo a procura por bens públicos. & STN/Siconfi & R\$ & \\
\hline Renda mediana (VE) & RMD & $\begin{array}{l}\text { Renda mediana desagregada das transferências no modelo com ilusão fiscal, possibilitando a } \\
\text { verificação do efeito flypaper. }\end{array}$ & IBGE & $\mathrm{R} \$$ & $(+)$ \\
\hline Tax share (VE) & TS & $\begin{array}{l}\text { Razão do imposto pago pelo eleitor mediano. Calculado pela divisão entre renda mediana } \mathrm{e} \\
\text { média. }\end{array}$ & IBGE & $\begin{array}{c}\text { Razão (Renda } \\
\text { Mediana/ } \\
\text { Renda Média) }\end{array}$ & $(-)$ \\
\hline População (VE) & POP & $\begin{array}{l}\text { Tamanho da população. A combinação com o coeficiente de tax share fornece o grau de } \\
\text { publicidade (congestionamento) dos gastos. }\end{array}$ & $\begin{array}{l}\text { STN/Siconfi } \\
\text { e IBGE }\end{array}$ & $\begin{array}{c}\text { População/ } \\
1000\end{array}$ & $(-)$ \\
\hline $\begin{array}{l}\text { Transferências } \\
\text { intergovernamentais per } \\
\text { capita (VE) }\end{array}$ & $\mathrm{TC}$ & $\begin{array}{l}\text { Transferências lump sum recebidas. Efeito positivo superior ao da renda confirma efeito } \\
\text { flypaper. Soma das participações de estados e municipios na receita da união (Estados: } \\
\text { Fundo de Participação dos Estados [FPE], Fundo de Participação dos Municipios [FPM], } \\
\text { Imposto Territorial Rural [ITR], Imposto sobre Produtos Industrializados [IPI], Contribuição } \\
\text { de Intervenção no Dominio Econômico [CIDE], Imposto sobre Operações Financeiras } \\
\text { [IOF]; Municipios: FPM, ITR, IOF Ouro) }\end{array}$ & STN/Siconfi & $\mathrm{R} \$$ & $(+)$ \\
\hline Simplicidade Fiscal (VE) & SFIS & Grau de concentração da receita (IHH) ponderado pelo indice de visibilidade (IV). & STN/Siconfi & Razão (0 a 1) & $(-)$ \\
\hline $\begin{array}{l}\text { Índice de Herfindahl- } \\
\text { Hirschman (VE) }\end{array}$ & $\mathrm{IHH}$ & $\begin{array}{l}\text { Grau de complexidade tributária, medida pela concentração da receita tributária. É dado pela } \\
\text { soma dos quadrados da participacão dos tributos na receita tributária. }\end{array}$ & STN/Siconfi & Razão (0 a 1) & $(-)$ \\
\hline $\begin{array}{l}\text { Indice de Visibilidade } \\
\text { (VE) }\end{array}$ & IV & $\begin{array}{l}\text { Nivel de visibilidade fiscal, calculado pela razão entre impostos diretos e receita tributária } \\
\text { total. }\end{array}$ & STN/Siconfi & Razão (0 a 1) & $(-)$ \\
\hline Mortalidade Infantil (VS) & MI & Crianças de até 1 (um) ano de idade mortas a cada 1.000 nascidas vivas. & IBGE & Razão (0 a 1) & \\
\hline $\begin{array}{l}\text { Razão de dependência } \\
\text { (VS) }\end{array}$ & DEP & $\begin{array}{l}\text { Representatividade da população até } 14 \text { anos e a partir de } 65 \text { anos, em relação à população } \\
\text { entre } 15 \text { e } 64 \text { anos. }\end{array}$ & IBGE & Razão (0 a 1) & \\
\hline $\begin{array}{l}\text { Taxa de envelhecimento } \\
\text { (VS) }\end{array}$ & TE & Representatividade da população acima de 65 anos. & IBGE & Razão (0 a 1) & \\
\hline $\begin{array}{l}\text { Taxa de atendimento } \\
\text { escolar (VS) }\end{array}$ & $\mathrm{ESC}$ & Razão da população entre 6 e 14 anos que frequenta a escola. & IBGE & Razão (0 a 1) & \\
\hline Índice de Gini (VS) & GINI & $\begin{array}{l}\text { Medida do grau de desigualdade na distribuição de renda. Quanto mais próximo de 1, maior } \\
\text { a desigualdade. }\end{array}$ & IBGE & Indice de 0 a 1 & \\
\hline
\end{tabular}
Siqueira (2016) aplicando a análise aos estados brasileiros no período de 2004 a 2015. O Quadro 1 apresenta as variáveis utilizadas na pesquisa.

Quadro 1 - Variáveis do estudo de evidências de ilusão fiscal

As informações da variável dependente gasto público per capita (DC), representada pelas despesas correntes nesta pesquisa, estão disponibilizadas pela Secretaria do Tesouro Nacional (STN). Os dados exclusivamente estaduais foram obtidos por meio das informações de execução orçamentária até 2013 e, para os períodos de 2014 e 2015, os dados foram obtidos no Sistema de Informações Contábeis e Fiscais do Setor 
Público Brasileiro (Siconfi). As informações municipais de 2004 a 2012 foram obtidas por meio da base de dados Finbra, disponibilizados também pela STN. De 2013 a 2015, foram consideradas as informações consolidadas dos municípios disponíveis no Siconfi/STN. A agregação dos dados de estados e municípios foi realizada porque há dados que são disponíveis somente a nível estadual, enquanto há dados disponíveis somente a nível municipal (Quadro 1), e a pesquisa realizada de forma agregada enriquece a análise e os resultados em relação à pesquisa somente em estados ou somente em municípios.

Os dados de rendimento médio e mediano utilizados nas variáveis RMD e TS foram obtidos por meio da Síntese de Indicadores Sociais (IBGE), por meio da tabela 6.6 - Rendimento mensal domiciliar per capita. A população foi obtida também por meio da Síntese de Indicadores Sociais (IBGE), enquanto que para a variável de transferências correntes per capita (TC), foram consideradas as transferências efetuadas pela União para estados e municípios, ou seja, a soma da participação dos entes subnacionais no Fundo de Participação de Estados e Distrito Federal (FPE), Fundo de Participação dos Municípios (FPM), Imposto sobre a Propriedade Territorial Rural (ITR), Imposto sobre Produtos Industrializados (IPI), Contribuição de Intervenção no Domínio Econômico (CIDE), Imposto sobre Operações de Crédito, Câmbio e Seguro, ou Relativas a Títulos ou Valores Mobiliários - Comercialização do Ouro (IOF-Ouro).

No cálculo do índice de simplicidade fiscal (SFIS), também foi considerada a base de dados de DC e TC. O índice de Herfindahl-Hirschman mede a complexidade da arrecadação tributária com base no peso dos tributos em relação à receita tributária total. Foram considerados os tributos Imposto Territorial e Predial Urbano (IPTU), Imposto de Renda (IR), Imposto sobre a Propriedade de Veículos Automotores (IPVA), Imposto sobre Transmissão Causa Mortis e Doação (ITCD), Imposto sobre a Transmissão de Bens Móveis (ITBI), Imposto sobre Circulação de Mercadorias e Serviços (ICMS), Imposto sobre Serviços (ISS), taxas e contribuições de melhoria para os dados exclusivamente estaduais e do Distrito Federal, com a inclusão de IPTU/ITR, IR, ITBI, ISS, taxas e contribuições de melhoria dos municípios.

O índice de visibilidade (IV) utilizado para ponderar o IHH no cálculo de SFIS representa a participação dos tributos diretos na receita tributária. Para dados estaduais, foi calculada a razão entre a soma dos tributos diretos e a receita tributária total. No cálculo, consideram-se os tributos diretos dos estados e do Distrito Federal (Imposto de Renda Retido na Fonte [IRRF], IPVA, ITCD, IPTU, taxas e contribuições de melhoria) e dos municípios (IPTU, IRRF, ITBI, taxas e contribuições de melhoria). Importante destacar que IPTU, ITBI e ISS constantes da base estadual são representados quase que exclusivamente pela arrecadação do Distrito Federal, o qual acumula competências tributárias estaduais e municipais.

As variáveis sociais foram utilizadas como variáveis de controle com base nos dados de 2010 do Censo Demográfico (IBGE). Para os demais exercícios foram utilizadas tabelas específicas da Síntese de Indicadores da Pesquisa Nacional por Amostra de Domicílios (PNAD/IBGE).

As informações de mortalidade infantil foram extraídas da Tabela 1.8 (Taxa de mortalidade infantil) da PNAD/IBGE, enquanto a taxa de dependência (DEP) e a taxa de envelhecimento (TE) são calculadas a partir das informações da Síntese de Indicadores Tabela 1.2 da PNAD/IBGE (Distribuição percentual da população residente). A taxa de atendimento escolar foi extraída do Programa Todos pela Educação, que indica o percentual da população entre 4 e 17 anos que frequenta a escola. Por fim, o índice Gini é disponibilizado a partir de 2004 na Tabela 6.3 da PNAD/IBGE.

A análise foi efetuada considerando dados consolidados de estados e municípios, de modo a verificar indícios de ilusão fiscal por Unidade da Federação. A partir da equação 9, o modelo completo a ser estimado está demonstrado a seguir, com base nos parâmetros de ilusão fiscal e utilização de logaritmo neperiano em todas as variáveis. As variáveis estão substituídas pelas siglas constantes do Quadro 1:

$$
\ln D C=\alpha+\beta_{t s} \ln T S+\beta_{\text {pop }} \ln P O P+\beta_{\text {rmd }} \ln R M D+\beta_{t c} \ln T C+\beta_{\text {sfis }} \ln S F I S+\Sigma \beta z
$$

Onde: 
Conforme Araújo (2014) e Araújo e Siqueira (2016), a equação 15 representa a relação entre população e a tax share que fornece o grau de publicidade dos bens, ou seja, se os bens têm características de público ou privado. Entretanto, tal mensuração não foi possível no presente trabalho, uma vez que a variável população foi utilizada em primeira diferença, inviabilizando a análise entre os coeficientes.

$$
\eta=\frac{\beta_{p o p}+\beta_{t s}+1}{\beta_{t s}+1}
$$

As variáveis (em logaritmo natural) foram submetidas a teste de estacionariedade, por meio da identificação de presença de raízes unitárias. Em seguida, foi definida a composição das estimações, considerando inicialmente o modelo mais completo (com as variáveis de ilusão fiscal) e os demais modelos com a exclusão, uma a uma, das variáveis de ilusão fiscal. Realizaram-se testes de autocorrelação serial, heterocedasticidade, estacionariedade, multicolinearidade, linearidade, normalidade dos resíduos e endogeneidade. Como método de análise, testou-se então seis modelos de demanda de gastos públicos considerando despesa corrente como variável dependente, viabilizando a análise proposta no objetivo inicial da pesquisa de analisar as evidências de ilusão fiscal no Brasil sob os aspectos do efeito flypaper e da ilusão causada pela complexidade da estrutura tributária.

\section{RESULTADOS}

O teste ADF-Fisher, que identifica a presença de raiz unitária individual apontou que para POP, IHH, IV, DEP, TE e GINI, em nível, não é possível rejeitar a hipótese nula de presença de raiz unitária. Quando testadas em primeira diferença, é possível rejeitar a hipótese nula para as cinco variáveis. O resultado do teste de estacionariedade para IHH defasada em um ano foi efetuado após as estimações dos modelos. De posse dos resultados dos testes de estacionariedade, a composição de todos os modelos foi definida, conforme consta do Quadro 2.

Quadro 2 - Composição dos modelos para cálculo das evidências de ilusão fiscal

\begin{tabular}{|l|l|l|l|}
\hline Modelo & $\begin{array}{l}\text { Variável } \\
\text { Dependente }(l \circ g)\end{array}$ & Variáveis Independentes $(l \circ g)$ & Variáveis sociais $(l \circ g)$ \\
\hline 1 & DC & d.POP; RMD; TS; TC; SFIS & MI; d.DEP; d.TE; ESC; d.GINI \\
\hline 2 & DC & d.POP; RMD; TS; SFIS & MI d.DEP; d.TE; ESC; d.GINI \\
\hline 3 & DC & d.POP; RMD; TS; TC; d.IHH; d.IV & MI; d.DEP; d.TE; ESC; d.GINI \\
\hline 3.1 & DC & d.POP; RMD; TS; TC; IHHdef; d.IV & MI; d.DEP; d.TE; ESC; d.GINI \\
\hline 4 & DC & d.POP; RMD; TS; d.IHH; d.IV & MI; d.DEP; d.TE; ESC; d.GINI \\
\hline 4.1 & DC & d.POP; RMD; TS; IHHdef; d.IV & MI; d.DEP; d.TE; ESC; d.GINI \\
\hline 5 & DC & d.POP; RMD; TS; TC & MI; d.DEP; d.TE; ESC; d.GINI \\
\hline 6 & DC & d.POP; RMD; TS & MI d.DEP; d.TE; ESC; d.GINI \\
\hline
\end{tabular}

Fonte: Elaboração própria. 1. as variáveis precedidas de “d." estão calculadas em primeira diferença; 2. A variável IHHdef representa IHH defasada em um período; 3 . A defasagem considera a observação do ano anterior para a variável, ou seja, verifica a resposta da variável dependente no período tem relação à variável independente em t-1. Siglas: DC: despesas correntes per capita; RMD: renda mediana; TS: tax share; POP: população;

TC: transferências intergovernamentais per capita; SFIS: simplicidade fiscal; IHH: índice de Herfindahl-

Hirschman de concentração da receita; IV: índice de visibilidade tributária; MI: mortalidade infantil; DEP: taxa de dependência; TE: taxa de envelhecimento; ESC: taxa de atendimento escolar; GINI: índice GINI de desigualdade.

Antes de os modelos serem estimados, testou-se a multicolinearidade entre os regressores de cada modelo através do fator de inflação da variância (FIV) e todos os índices FIV foram inferiores a 5, não sendo necessário qualquer tratamento nas variáveis (Gujarati \& Porter, 2011; Fávero, 2013). 
Tabela 1 - Teste de Mulcolinearidade dos modelos para cálculo das evidências de ilusão fiscal

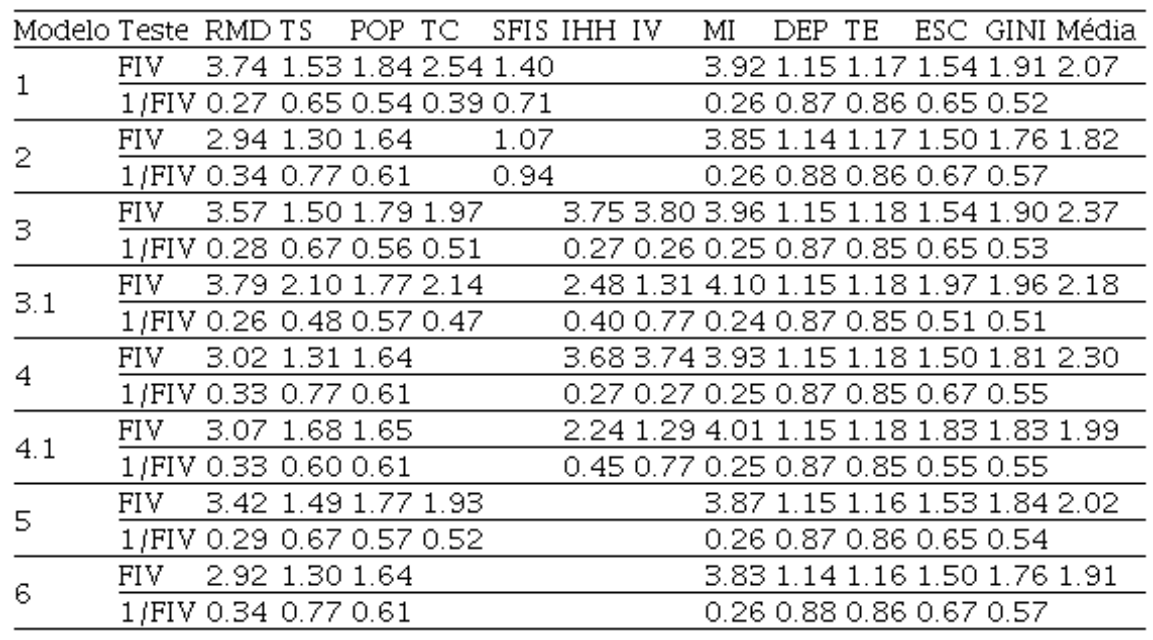

Fonte: Elaboração própria. Siglas: FIV: Fator de Inflação da Variância; RMD: renda mediana; TS: tax share; POP: população; TC: transferências intergovernamentais per capita; SFIS: simplicidade fiscal; IHH: índice de HerfindahlHirschman de concentração da receita; IV: índice de visibilidade tributária; MI: mortalidade infantil; DEP: taxa de dependência; TE: taxa de envelhecimento; ESC: taxa de atendimento escolar; GINI: índice Gini de desigualdade.

Para a estimação, considerando tratar-se de regressão com dados em painel, foram aplicados aos modelos completos testes para a escolha do modelo mais adequado (pooled, efeitos fixos ou efeitos aleatórios) e o modelo de efeitos fixos mostrou-se mais adequado para todas as descrições.

Tabela 2 - Testes para escolha entre pooled, efeitos fixos e efeitos aleatórios

\begin{tabular}{|c|c|c|c|c|}
\hline Modelos & Teste de Chow (F) & Teste de Breush-Pagan & Teste de Hausman & Modelo aplicável \\
\hline \multirow[b]{2}{*}{$\bmod 2$} & $\mathrm{~F}(26,261)=89.93$ & chibar $2(01)=631.73$ & $\operatorname{chi} 2(9)=69.83$ & \multirow{2}{*}{ Efeitos Fixos } \\
\hline & Prob $>F=0.0000$ & Prob $>$ chibar $2=0.0000$ & Prob>chi2 $=0.0000$ & \\
\hline \multirow{2}{*}{$\bmod 4$} & $F(26,260)=93.44$ & chibar $2(01)=658.24$ & $\operatorname{chi} 2(10)=56.80$ & \multirow{2}{*}{ Efeitos Fixos } \\
\hline & Prob $>F=0.0000$ & Prob $>$ chibar $2=0.0000$ & Prob $>$ chi $2=0.0000$ & \\
\hline \multirow[b]{2}{*}{$\bmod 4.1$} & $F(26,260)=97.56$ & chibar $2(01)=716.07$ & $\operatorname{chi} 2(10)=45.00$ & \multirow[b]{2}{*}{ Efeitos Fixos } \\
\hline & Prob $>F=0.0000$ & Prob $>$ chibar $2=0.0000$ & Prob>chi2 $=0.0000$ & \\
\hline \multirow{2}{*}{$\bmod 5$} & $F(26,261)=51.05$ & chibar $2(01)=628.89$ & $\operatorname{chi} 2(9)=41.77$ & \multirow{2}{*}{ Efeitos Fixos } \\
\hline & Prob $>F=0.0000$ & Prob $>$ chibar $2=0.0000$ & Prob>chi2 $=0.0000$ & \\
\hline \multirow{2}{*}{$\bmod 6$} & $F(26,262)=94.63$ & chibar $2(01)=679.23$ & $\operatorname{chi} 2(8)=53.22$ & \multirow{2}{*}{ Efeitos Fixos } \\
\hline & Prob $>F=0.0000$ & Prob $>$ chibar $2=0.0000$ & Prob>chi2 $=0.0000$ & \\
\hline
\end{tabular}

Fonte: Elaboração própria. Na especificação do teste de Hausman, foi incluída a opção "sigmamore" que especifica que as matrizes de covariância se baseiam na variação de perturbação estimada do estimador eficiente. Essa opção é recomendada na comparação entre efeitos fixos e efeitos aleatórios, porque é menos propensa a produzir uma matriz de covariância diferenciada definida não positiva (Statacorp, 2015).

Ademais, foram efetuados os testes de Wooldridge para autocorrelação serial e de Wald modificado para heterocedasticidade em grupo (Wooldrigde, 2002; Greene, 2000). Os resultados demonstraram que, para todos os modelos, é possível rejeitar as hipóteses nulas dos dois testes, indicando presença de problemas de autocorrelação e heterocedasticidade. Nessa situação, é sugerido que seja utilizado um modelo robusto contra ambos os problemas, disponível no software Stata 15 (Arellano, 2003, 1987; Wooldridge, 2013). 
Tabela 3 - Testes de Autocorrelação e Heterocedasticidade

\begin{tabular}{|c|c|c|c|c|c|}
\hline \multirow{3}{*}{ Modelo } & Autocorrelação & Heterocedasticidade & & Autocorrelação & Heterocedasticidade \\
\hline & $F(1,26)$ & chi2 (27) & Modelo & $F(1,26)$ & chi2 (27) \\
\hline & (Prob > F ) & (Prob >chi2) & & $($ Prob $>F)$ & (Prob $>$ chi2) \\
\hline \multirow{2}{*}{1} & 54.154 & 2007.71 & & 56.643 & 1045.21 \\
\hline & $(0.0000)$ & $(0.0000)$ & & $(0.0000)$ & $(0.0000)$ \\
\hline \multirow{2}{*}{2} & 47.277 & 1020.39 & & 43.418 & 344.84 \\
\hline & $(0.0000)$ & $(0.0000)$ & 4.1 & $(0.0000)$ & $(0.0000)$ \\
\hline \multirow{2}{*}{3} & 61.835 & 1882.48 & & 52.158 & 2455.76 \\
\hline & $(0.0000)$ & $(0.0000)$ & & $(0.0000)$ & $(0.0000)$ \\
\hline \multirow{2}{*}{3.1} & 42.685 & 513.94 & & 38.313 & 941.11 \\
\hline & $(0.0000)$ & $(0.0000)$ & & $(0.0000)$ & $(0.0000)$ \\
\hline
\end{tabular}

Fonte: Elaboração própria. 1. Teste de Wooldrigde para autocorrelação serial: H0 - não existe correlação de $1^{\text {a }}$ ordem (não apresenta autocorrelação), H1 - existe correlação de $1^{\text {a }}$ ordem (apresenta autocorrelação); 2. Teste

Wald modificado para heterocedasticidade em grupo: $\mathrm{H} 0$ - homocedasticidade, $\mathrm{H} 1$ - heterocedasticidade.

Consideradas atendidas as premissas de regressão múltipla (estacionariedade, ausência de multicolinearidade, ausência de autocorrelação, homocedasticidade, linearidade, normalidade dos resíduos e ausência de endogeneidade), há evidências de que as estimações efetuadas são consistentes para análise. Dessa forma, apresentam-se na Tabela 4 os resultados obtidos.

Tabela 4 - Estimações do modelo de demanda por gasto público dos estados e municípios

\begin{tabular}{|c|c|c|c|c|c|c|c|c|c|c|c|c|c|c|c|c|}
\hline $\begin{array}{l}\text { Variáveis } \\
(\log )\end{array}$ & Mod 1 & & $\operatorname{Mod} 2$ & & Mod 3 & & Mod 3. & & Mod 4 & & Mod 4 & & Mod 5 & & Mod 6 & \\
\hline Variável De & endente & e: DC & & & & & & & & & & & & & & \\
\hline POP & -1.19 & $* * *$ & -1.20 & $* * *$ & -1.22 & $* * *$ & -1.13 & $* * *$ & -1.18 & $* * *$ & -1.21 & $* * *$ & -1.19 & $* * *$ & -1.21 & $* * *$ \\
\hline RMD & 0.19 & $* *$ & 0.28 & $* * *$ & 0.16 & $* * *$ & 0.09 & & 0.28 & $* * *$ & 0.21 & $* * *$ & 0.19 & $* *$ & 0.28 & $* * *$ \\
\hline TS & -0.33 & $* * *$ & -0.42 & $* * *$ & -0.30 & $* * *$ & -0.15 & * & -0.42 & $* * *$ & -0.25 & $* *$ & -0.33 & $* * *$ & -0.42 & $* * *$ \\
\hline $\mathrm{TC}$ & 0.28 & $* * *$ & & & 0.34 & $* * *$ & 0.30 & $* * *$ & & & & & 0.27 & $* * *$ & & \\
\hline SFIS & 0.09 & & -0.06 & & & & & & & & & & & & & \\
\hline IHH & & & & & 0.30 & $* *$ & -0.51 & $* * *$ & -0.10 & & -0.49 & $* * *$ & & & & \\
\hline IV & & & & & 0.15 & & 0.14 & $* * *$ & -0.07 & & 0.23 & $* * *$ & & & & \\
\hline MI & -0.74 & $* * *$ & -0.88 & $* * *$ & -0.65 & & -0.58 & $* * *$ & -0.88 & $* * *$ & -0.76 & $* * *$ & -0.75 & $* * *$ & -0.88 & $* * *$ \\
\hline DEP & -0.04 & & 0.01 & & -0.01 & & -0.02 & & 0.00 & & 0.03 & & -0.04 & & 0.01 & \\
\hline TE & 0.01 & & 0.00 & & 0.01 & & 0.01 & & 0.00 & & 0.00 & & 0.01 & & 0.00 & \\
\hline ESC & 2.63 & $* * *$ & 3.30 & $* * *$ & 2.91 & $* * *$ & 2.13 & $* * *$ & 3.26 & $* * *$ & 2.64 & $* * *$ & 2.65 & $* * *$ & 3.30 & $* * *$ \\
\hline GINI & -0.12 & & -0.21 & $*$ & -0.12 & & -0.03 & & -0.20 & $*$ & -0.09 & & -0.13 & & -0.20 & $*$ \\
\hline d1 & 0.44 & $* * *$ & 0.41 & $* * *$ & 0.44 & $* * *$ & 0.46 & $* * *$ & 0.41 & $* * *$ & 0.43 & $* * *$ & 0.44 & $* * *$ & 0.41 & $* * *$ \\
\hline d2 & & & 0.28 & $* * *$ & 0.28 & $* * *$ & & & 0.28 & $* * *$ & & & & & 0.28 & $* * *$ \\
\hline d3 & & & -0.26 & $* * *$ & & & & & -0.26 & $* * *$ & & & & & -0.26 & $* * *$ \\
\hline $\begin{array}{l}\text { Constante } \\
\text { Estatísticas }\end{array}$ & 2.48 & $* *$ & 2.89 & $* * *$ & 2.48 & $* * *$ & 3.19 & $* * *$ & 3.05 & $* * *$ & 3.75 & $* * *$ & 2.28 & $* *$ & 3.03 & $* * *$ \\
\hline$R^{2}-a$ & 0.8693 & & 0.8639 & & 0.884 & & 0.8927 & & 0.863 & & 0.864 & & 0.8692 & & 0.864 & \\
\hline $\mathrm{AIC}$ & -770.6 & & -761.8 & & -807.8 & & -822.5 & & -760.5 & & -759.2 & & -771.5 & & -763.3 & \\
\hline $\mathrm{BIC}$ & -733.7 & & -728.5 & & -767. & & -781.9 & & -723 & & -722.2 & & -738.3 & & -733.7 & \\
\hline Teste F & 106.35 & & 115.53 & & 118.8 & & 145.75 & & 108.5 & & 134.15 & & 125.66 & & 128.2 & \\
\hline$F(p$-valor) & 0.0000 & & 0.0000 & & 0.000 & & 0.0000 & & 0.0000 & & 0.0000 & & 0.0000 & & 0.000 & \\
\hline $\begin{array}{l}\text { JB } \\
\text { (p-valor)( }\end{array}$ & 0.0934 & & 0.1727 & & $0.145^{\circ}$ & & 0.1253 & & 0.154 & & 0.0673 & & 0.0754 & & $0.207 k$ & \\
\hline
\end{tabular}

Fonte: Elaboração própria. ${ }^{*},{ }^{* *} \mathrm{e}^{* * *}$ significância a $10 \%, 5 \%$ e de $1 \%$, respectivamente. Siglas: DC: despesas correntes per capita; RMD: renda mediana; TS: tax share; POP: população; TC: transferências intergovernamentais per capita; SFIS: simplicidade fiscal; IHH: índice de Herfindahl-Hirschman de concentração da receita; IV: índice de visibilidade tributária; MI: mortalidade infantil; DEP: taxa de dependência; TE: taxa de envelhecimento; ESC: taxa de atendimento escolar; GINI: índice GINI de desigualdade; d1, d2 e d3: variáveis dummies de controle de outliers. 
Os resultados dos testes $\mathrm{F}$ apresentam que os modelos são globalmente significativos. Os altos valores de $\mathrm{R}^{2}$, também observados nos trabalhos de referência, podem ser decorrentes da quantidade de variáveis do modelo. Em geral, índices de $\mathrm{R}^{2}$ não podem ser considerados, imediatamente, representativos de bom ajustamento dos modelos, uma vez que podem sugerir presença de multicolinearidade ou endogeneidade. No entanto, conforme exposto anteriormente, esses problemas foram descartados. Quanto aos índices de ajustamento do modelo ( $\mathrm{R}^{2}$, AIC e BIC), os valores convergem para a escolha do modelo 3.1 como mais adequado.

Em relação ao comportamento esperado das variáveis, o coeficiente da variável população (POP) apresenta sinal negativo em todas as estimações. De acordo com Araújo (2014), associa-se esse comportamento ao ganho de escala no fornecimento de bens e serviços públicos nas grandes cidades. Cabe notar que em todas as estimações a variável POP mostrou-se significativa. Porém, o ganho de escala que justificaria essa relação é abordado por outros pesquisadores (Oates, 1988; Edwards, 1990; Means \& Mehay, 1995; Reiter \& Weichenrieder, 1997) pode não evidenciar que as maiores cidades possuem menores gastos que as pequenas cidades, conforme ressalta Araújo (2014). A redução dos custos de fornecimento dos bens e serviços nas grandes cidades conduz a maior demanda por esses bens, fazendo com que eles gastem mais de uma forma geral do que os municípios menores (Buettner \& Holm-Hadulla, 2013).

A variável de renda mediana (RMD), sem significância apenas em 3.1, retornou o sinal positivo esperado. A variável tax share (TS), significativa em todas as estimações, apresenta sinal negativo esperado. A variável de transferências correntes lump sum per capita (TC), a primeira de ilusão fiscal inserida nas especificações, é significativa nas quatro aparições na Tabela 4, com sinal positivo esperado, indicando uma relação direta entre o aumento das transferências e do gasto público per capita. A variável de simplicidade fiscal (SFIS) não se mostrou significativa em nenhum dos modelos, mas o índice de Herfindahl-Hirschman (IHH) apresentou significância estatística nos modelos 3, 3.1 e 4.1. No entanto, no modelo 3, o sinal observado difere do esperado. O índice de visibilidade (IV) apresentou significância estatística nos modelos 3.1 e 4.1, porém com sinal diferente do esperado. Ambos os modelos consideram a variável IHH defasada em um exercício. Como os resultados retornados apresentaram a mencionada significância, há indícios de que o gasto público per capita se relacione inversamente ao nível de complexidade tributária com um ano de defasagem e diretamente ao nível de visibilidade tributária. Os resultados corroboram então a teoria da ilusão fiscal, a qual estabelece que quanto maior o nível de complexidade tributária, maior é o gasto público per capita. Essa relação inversamente proporcional observada converge à ideia de que no Brasil escolhas políticas representam os interesses dos representantes (teoria da escolha pública), em contraposição às preferências do eleitor de renda mediana (teoria eleitor mediano). Logo, essas evidências adicionadas à teoria do efeito flypaper indicam que as teorias se aplicam e reforçam a existência de ilusão fiscal na estrutura tributária brasileira.

$\mathrm{Na}$ análise das evidências de ilusão fiscal a partir dos modelos estimados, considera-se o modelo completo 3.1 como referência, com base nos seguintes critérios: Ter apresentado os melhores índices de ajustamento; as variáveis relativas à estrutura tributária (IHHdef e IV) mostraram-se significativas tanto em 3.1 quanto em 4.1; a análise quanto às transferências lump sum é aplicável aos demais modelos em que é incluída. Assim, será comparado o comportamento das variáveis em 6, 5, 4.1 e 3.1, iniciando pelo modelo que não contém quaisquer variáveis de ilusão, conforme Tabela 5.

Tabela 5 - Estimações selecionadas com e sem variáveis de IF

\begin{tabular}{|c|c|c|c|c|c|}
\hline Variáveis $(\log )$ & Mod 6 & Mod 5 & Mod 4.1 & Mod 3. & \\
\hline POP & $-1.21^{* * *}$ & $-1.19 * 8 *$ & $-1.21 * * *$ & -1.13 & **** \\
\hline TS & $-0.42 * * *$ & $-0.33^{* 8 *}$ & $-0.25 * 8$ & -0.15 & $*$ \\
\hline IHH & & & $-0.49^{* * *}$ & -0.51 & $* 8 *$ \\
\hline IV & & & $0.23 * * *$ & 0.14 & $* * *$ \\
\hline Constante & $3.03^{* * *}$ & $2.28 * 8$ & $3.75^{* * *}$ & 3.19 & **** \\
\hline VS & SIM & SIM & SIM & SIM & \\
\hline
\end{tabular}




\begin{abstract}
Fonte: Elaboração própria. 1. ${ }^{*},{ }^{* *} \mathrm{e}^{* * *}$ significância a 10\%, $5 \%$ e de $1 \%$, respectivamente; 2 . Modelos estimados em função da despesa corrente per capita. Siglas: RMD: renda mediana; TS: tax share; POP: população; TC: transferências intergovernamentais per capita; SFIS: simplicidade fiscal; IHH: índice de Herfindahl-Hirschman de concentração da receita; IV: índice de visibilidade tributária; VS: variáveis sociais.
\end{abstract}

Comparando-se os modelos 6 e 5, com a incorporação da variável de transferências correntes lump sum (TC), as variáveis renda mediana (RMD) e tax share (TS) apresentam relevante redução, convergentes com os resultados de Araújo (2014) e Araújo e Siqueira (2016). Entretanto, o tamanho da população (POP) sofre pouca mudança, diferente dos trabalhos mencionados, que observaram inversão de sinal.

Quanto ao modelo 4.1, que incorpora as variáveis de complexidade e visibilidade tributária (IHH defasado e IV) ao modelo sem as variáveis de ilusão fiscal, observa-se comportamento semelhante ao verificado com a inclusão de TC. A variável de população não apresentou variação. No entanto, TS apresentou uma variação superior à observada anteriormente. Especificamente quanto às variáveis IHH e IV, o resultado observado é parcialmente coerente com a hipótese de que um sistema mais simples tributariamente possibilita o aumento do gasto público. Isso porque apenas a variável IHH apresentou o sinal esperado com base na literatura, indicando que a pulverização de tributos tende a possibilitar um aumento do gasto público. No caso do presente trabalho essa relação só foi encontrada com a defasagem de IHH. Todavia, quanto ao índice de visibilidade (IV), o coeficiente encontrado apresentou sinal positivo, não sendo possível corroborar a teoria de que impostos mais visíveis (diretos) reduzem a possibilidade de práticas ilusórias.

Em relação ao modelo 3.1, que incorpora todas as variáveis de ilusão fiscal, é possível verificar que as variáveis POP, RMD e TS sofrem redução ainda maior, reforçando os resultados apresentados em 5 e 4.1 . Especificamente quanto à RMD, a variável não se mostrou significativa no modelo.

Analisando a magnitude dos coeficientes dos modelos, observa-se que, condizente com as características de ilusão fiscal provocada pelo efeito flypaper. Os resultados são aderentes aos obtidos por Araújo (2014) e Araújo e Siqueira (2016), que identificaram o efeito flypaper com base em dados municipais. Dessa forma, considera-se que o presente trabalho obteve evidências do efeito flypaper com base em dados agregados dos estados e municípios, tendo em vista que as transferências lump sum apresentaram coeficiente superior ao da renda mediana em relação ao gasto público. Esses resultados reforçam que as transferências lump sum realmente causam maior efeito no estímulo do gasto público do que o aumento na renda local (teoria do efeito flypaper). Portanto, empiricamente, conclui-se que os contribuintes estão mais dispostos a aceitar aumentos nas despesas públicas quando as receitas aumentam, mesmo que por meio de transferências intergovernamentais, do que quando há um aumento na renda privada.

Em relação às variáveis de controle utilizadas, o índice de dependência (DEP) e a taxa de envelhecimento (TE) não se mostraram significativos nos modelos. A taxa de mortalidade infantil (MI) apresentou significância estatística em todos os modelos reportados, retornando uma relação inversa com o gasto público per capita. Já a taxa de atendimento escolar (ESC), também significante em todos os modelos, apresentou relação positiva com o gasto público per capita.

Por fim, a relação encontrada entre o índice Gini de desigualdade e o gasto público foi negativa, significativa nos modelos 2, 4 e 6, a 10\% de significância. É interessante observar que esses resultados apontam para uma tendência de menor nível de gasto público em locais com indicadores que caracterizam pobreza, merecendo atenção para estudos específicos. Esses resultados demonstram, à luz teoria da escolha pública, que nos locais com muita concentração de renda (alto índice de Gini) as políticas públicas são realizadas com base nas preferências dos representantes ou governantes, levando ao menor nível de gasto e atendendo principalmente às preferências citadas.

Com base nas variáveis e estimações analisadas, a pesquisa apresenta evidências de ilusão fiscal sob dois aspectos:

a) Complexidade na arrecadação tributária: Essa característica foi demonstrada pelo comportamento de IHH defasado nas estimações. Assim, há a tendência de subestimação da carga tributária pelos contribuintes, de modo que aceitem níveis mais altos de tributação. Essa evidência deve ser tomada com cuidado, uma vez 
que sem a defasagem a variável se mostrou significativa no modelo completo, mas retornou sinal diverso daquele esperado pela literatura;

b) Efeito flypaper: Considerando que as despesas correntes são mais sensíveis a variações nas transferências correntes do que a variações na renda, conforme observado também pela magnitude dos parâmetros das variáveis e pela relação nas estimações completas.

Coerente com Araújo (2014) e Araújo e Siqueira (2016), o financiamento do gasto público por meio de transferências não condicionadas amplia a distância entre o pagamento de impostos e o recebimento de bens e serviços, diminuindo a percepção dos contribuintes quanto ao real custo dos serviços públicos e permitindo a expansão de gastos. Ou seja, os resultados convergem à ideia de que as transferências lump sum, recebidas por estados e municípios, favorecem a ampliação das despesas governamentais.

\section{CONSIDERAÇÕES FINAIS}

O objetivo do presente trabalho foi atingido, uma vez que se apresentou análise das evidências de ilusão fiscal no Brasil sob os aspectos do efeito flypaper e da ilusão causada pela complexidade da estrutura tributária, com base em dados agregados de estados e municípios. Os resultados apontaram evidências de ilusão fiscal sob as óticas do efeito flypaper e da complexidade tributária.

No primeiro caso, o cálculo efetuado com base no modelo do eleitor mediano demonstrou que os gastos públicos são mais sensíveis às transferências não condicionadas da União para estados e municípios do que ao crescimento na renda mediana, corroborando a existência de efeito flypaper no Brasil. Adicionalmente, constatou-se que os contribuintes estão mais dispostos a aceitar aumentos nas despesas públicas quando as receitas aumentam, mesmo que por meio de transferências intergovernamentais, do que quando há um aumento na renda privada.

Os resultados obtidos relativos ao efeito flypaper convergem a estudos anteriores referentes ao ambiente fiscal brasileiro (Cossio \& Carvalho, 2001; Guedes \& Gasparini, 2007; Varela, Martins, \& Fávero, 2010; Mattos, Rocha, \& Arvate, 2011; Sakurai, 2013; Araújo; 2014; Araújo \& Siqueira, 2016; Diniz, Lima, \& Martins, 2017).

Quanto à complexidade tributária, foram obtidas evidências de que quanto maior o índice de HerfindahlHirschman de concentração da receita, menor o gasto público per capita dos estados e municípios, para o período da amostra (2004 a 2015), quando defasado em um período. Tal resultado significa que quanto mais simples uma estrutura tributária, no que diz respeito à quantidade de impostos, menor o incentivo para aumento do gasto público. Logo, o ideal é que se simplifique a estrutura tributária brasileira para que o gasto público também diminua, viabilizando, inclusive, progresso econômico e investimento externo.

No entanto, não foram encontrados resultados que ratificassem a hipótese de Mill, que supõe que quanto maior a representatividade de tributos indiretos, maior a dificuldade de percepção da carga tributária por parte dos contribuintes, ou seja, maior a ilusão fiscal. Nesse caso, a variável de visibilidade tributária, que representa a razão entre impostos diretos e arrecadação, apresentou comportamento diferente do estipulado na literatura, uma vez que a correlação encontrada com o proxy de demanda por bens públicos foi positiva. Por fim, a identificação das características da estrutura fiscal de estados e municípios demonstrou que o peso dos tributos indiretos supera significativamente o dos diretos.

De posse dos resultados, tanto os observados quanto ao efeito flypaper quanto àqueles relativos à estrutura tributária, observa-se que o ambiente fiscal brasileiro é propício à existência de ilusão fiscal. No primeiro caso, o alto grau de dependência dos entes subnacionais em relação às receitas geradas em âmbito federal permite que os gastos públicos estejam menos vinculados às demandas dos contribuintes, uma vez que estes percebem em menor grau a geração de receitas. No caso da estrutura tributária, apesar dos resultados não ratificarem a hipótese de Mill, a quantidade de tributos existentes facilita a ocorrência de ilusão fiscal, também permitindo que os gastos públicos sejam menos aderentes aos interesses dos indivíduos. 
Assim, é possível inferir que são de grande relevância os estudos para implantação de um sistema tributário que simplifique o ambiente fiscal brasileiro, tornando mais visíveis aos contribuintes os tributos e, consequentemente, os gastos governamentais que lhes beneficiam. Dessa forma, há uma tendência de criação de um ambiente que permita um maior controle social e espera-se que este afete, inclusive, decisóes relativas à política fiscal.

Considerando os resultados obtidos e as características pontuadas, vislumbra-se como possibilidade de estudos futuros análise de evidências de ilusão fiscal sem a agregação de dados utilizada neste trabalho, de modo a aumentar a quantidade de observações. Além disso, verificação dos efeitos de variáveis de ilusão fiscal sobre o gasto público sobre o PIB, diferentemente do valor per capita, bem como exploração de outros modelos econométricos e e adição de mais variáveis.

\section{REFERENNCIAS}

Araújo, J. M., \& Siqueira, R. B. (2016). Demanda por gastos públicos locais: evidências dos efeitos de ilusão fiscal no Brasil. Estudos Econômicos, São Paulo, 46(1), 189-219.

Araújo, J. M. (2014). Um estudo sobre ilusão fiscal no Brasil. Tese (Doutorado em Economia) - Universidade Federal de Pernambuco, Centro de Ciências Sociais Aplicadas, Recife.

Arellano, M. (2003). Panel Data Econometrics. Oxford: Oxford University Press.

Arellano, M. (1987). Computing Robust Standard Errors for Within Group Estimators. Oxford Bulletin of Economics and Statistics, 49(4), 431-434.

Bergstrom, T. C., \& Goodman, Robert P. (1973). Private demands for public goods. The American Economic Review, Pittsburgh, 63(3), 280-296.

Borcherding, T. E., \& Deacon, R. T. (1972). The demand for the services of non-federal governments. The American Economic Review, Pittsburgh, 62(5), 891-901.

Buettner, Thiess, \& Holm-Hadulla, Fédéric. (2013). City size and the demand for local public goods. Regional Science and Urban Economics, 43(1), 16-21.

Carvalho, D. F., Oliveira, C. C. R., \& Carvalho, A. C. (2009). Desigualdades econômicas inter-regionais, capacidade tributária e esforço fiscal dos estados da Amazônia (1970-2000): uma abordagem econométrica de fronteira estocástica. Novos Cadernos NAEA, Belém, 10(2).

Cossío, F. A. B., \& Carvalho, L. M. (2001). Os efeitos expansivos das transferências intergovernamentais e transbordamentos espaciais das despesas públicas: evidências para os municípios brasileiros-1996. Pesquisa e Planejamento Econômico, 31(1), 75-124.

Cossío, F. A. B. (1998). Disparidades econômicas inter-regionais, capacidade de obtenção de recursos tributários, esforço fiscal e gasto público no federalismo brasileiro. Dissertação (Mestrado em Economia) - PUCRJ, $21^{\circ}$ Prêmio BNDES de Economia, Rio de Janeiro.

Courant, P., Gramlich, E., \& Rubinfeld, D. (1978). The stimulative effects of intergovernmental grants: Or why money sticks where it hits. Fiscal federalism and grants-in-aid, n. January, 5-21.

Craig, E. D., \& Heins, A. J. (1980). The effect of tax elasticity on government spending. Public Choice, Logan, 35(3), 267-275.

Diniz, J. A.; Lima, R. H.; Martins, V. G. (2017). O Efeito Flypaper no Financiamento da Educação Fundamental dos Municípios Paraibanos. Administração Pública e Gestão Social, 9(2), 95-104.

Dollery, B. E., \& Worthington, A. C. (1996). The empirical analysis of fiscal illusion. Journal of Economic Surveys, 10(3), 261-297.

Dollery, B. E., \& Worthington, A. C. (1995a) State expenditure and fiscal illusion in Australia: A test of the revenue complexity, revenue elasticity and Flypaper hypotheses. Economic Analysis and Policy, 25(2), 125-140.

Dollery, B., \& Worthington, A. (1995b). Federal Expenditure and Fiscal Illusion: A Test of the Flypaper Hypothesis in Australia. Publius, 25(1), 23-34. 
Edwards, John HY. (1990). Congestion function specification and the "publicness" of local public goods. Journal of Urban Economics, 27(1), 80-96.

Fávero, L. P. L. (2013). Dados em painel em contabilidade e finanças: teoria e aplicação. Brazilian Business Review, $10(1), 131-156$,

Gemmell, N., Morrissey, O., \& Pinar, A. (2002). Fiscal illusion and political accountability: theory and evidence from two local tax regimes in Britain. Public Choice, Logan, 110(3), 199-224.

Greene, W. (2000). Econometric Analysis. Upper Saddle River, NJ: Prentice-Hall.

Grossman, P. J. (1990). The Impact of Federal and State Grants on Local Government Spending: a Test of the Fiscal Illusion Hypothesis. Public Finance Quarterly, 18(3), 313-327.

Guedes, K. P., \& Gasparini, C. E. (2007). Descentralizaçao fiscal e tamanho do governo no Brasil. Economia Aplicada, 11(2), 303-323,.

Gujarati, Damodar N., \& Porter, Dawn C. (2011). Econometria básica. 5. Porto Alegre, AMGH.

Hammes, D. L., \& Wills, D. T. (1987). Fiscal illusion and the grantor government in Canada. Economic Inquiry, 25(4), 707-713.

Inman, R. P. (2008). The Flypaper Effect. National Bureau of Economic Research Working Paper Series, 9, 217-226.

Kusuma, H. (2017). Flypaper Effect\#: Fiscal Illusion and Bureaucratic Model. Jesp, 9(1), 27-39.

Logan, R. R. (1986). Fiscal Illusion and Grantor Government. Journal of Political Economy, 94(6), 1304-1318.

Massardi, W. O., \& Abrantes, L. A. (2016). Dependência dos municípios de Minas Gerais em relação ao FPM. Revista de Gestão, Finanças e Contabilidade, 1(6), 173-187.

Mattos, E., Rocha, F., \& Arvate, P. (2011). Flypaper effect revisited: evidence for tax collection efficiency in Brazilian municipalities. Estudos Econômicos, 41(2), 239-267.

Means, Tom S., \& Mehay, Stephen L. (1995). Estimating the publicness of local government services: Alternative congestion function specifications. Southern Economic Journal, 61(3), 614-627.

Mendes, C. C., \& Sousa, M. C. S. (2006). Estimando a demanda por serviços públicos nos municípios brasileiros. Revista Brasileira de Economia, 60(3), 281-296.

Menezes, R. T., Saiani, C. C. S., \& Zoghbi, A. C. P. (2011). Demanda mediana por serviços públicos e desempenho eleitoral: evidências do modelo do eleitor mediano para os municípios brasileiros. Estudos Econômicos, 41(1), 25-57.

Morais, H. A. R., \& Bonifácio, J. N. S. (2016). Transferências constitucionais: uma análise da representatividade do fundo de participação dos municípios para a região do Alto Oeste Potiguar. Tekhne e Logos, Botucatu, 7(2), 16-32.

Mourão, P. (2007). The Economics of Illusion -a discussion based on Fiscal Illusion. Journal of Public Finance and Public Choice, XXV(1), 67-86.

Mourão, P. J. R. (2008). Towards a Puviani’s fiscal illusion index. Hacienda Publica Espanola. Revista de Economía Pública, 187(4), 49-86.

Munley, V. G., \& Greene, K. V. (1978). Fiscal illusion, the nature of public goods and equation specification. Public Choice, 33(1), 95-100.

Nascimento, J. S. (2010). Efeitos das transferências financeiras sobre os gastos e a arrecadação dos municípios brasileiros. Tese (Doutorado) - Universidade Federal de Viçosa, Viçosa.

Oates, W. E. (1999). An Easy on Fiscal Federalism. Journal of Economic Literature, 37(3), 1120-1149.

Oates, W. E. (1988). On the nature and measurement of fiscal illusion: a survey. In Brennan et al. (eds). Taxation and Fiscal Fereralism: Essays in Honor of Russel Mathews. Camberra, 65-82.

Oates, W. E. (1979). Lump-sum Intergovernmental Grants have Price Effects. In P. Mieszkowski and W. Oakland (ed). Fiscal Federalism and Grants-in-Aid. Washington D.C: The Urban Institute.

Oates, W. E. (1975). Automatic Increases in Tax Revenues - The Effect on the Size of the Public Budget. In W.E Oates (ed). Financing the New Federalism: Revenue Sharing Conditional Grants and Taxation. Baltimore: John Hopkins University Press. 
Reiter, M., \& Weichenrieder, A. (1997). Are public goods public? A critical survey of the demand estimates for local public services. FinanzArchiv/Public Finance Analysis, 374-408.

Sakurai, S. N. (2013). Efeitos assimétricos das transferências governamentais sobre os gastos públicos locais: evidências em painel para os municípios brasileiros. Pesquisa e Planejamento Econômico PPE. Rio de Janeiro, 43(2), 309-332.

Statacorp. (2015). Stata 15. Base Reference Manual. College Station, TX: Stata Press.

Varela, P. S., Martins, G. A., \& Fávero, L. P. L. (2010). Ineficiência do gasto público e ilusão fiscal: uma avaliação do Flypaper effect na atenção básica à saúde. Congresso Anpcont, Anais. Natal, RN, Brasil.

Veloso, J. F. A. (2008). As transferências intergovernamentais e o esforço tributário municipal: uma análise do fundo de participação dos municípios (FPM). Dissertação (Mestrado) - Universidade Católica de Brasília, Brasília.

Wagner, R. E. (1976). Revenue structure, fiscal illusion, and budgetary choice. Public Choice, Logan, 25(1), 45-61.

Winer, S. L. (1983). Some Evidence on the Effect of the Separation of Spending and Taxing Decisions. Journal of Political Economy, 91(1), 126-140.

Wooldridge, J. M. (2013). Introductory Econometrics: A Modern Approach. 5.ed. Mason, OH: South-Western.

Wooldridge, J. M. (2002). Econometric Analysis of Cross Section and Panel Data. Cambridge, MA: MIT Press.

Yu, Y., Wang, J., \& Tian, X. (2016). Identifying the Flypaper Effect in the Presence of Spatial Dependence: Evidence from Education in China's Counties. Growth and Change, 47(1), 93-110.

\section{Apêndice - Testes ADF-Fisher de Raiz Unitária}

\begin{tabular}{|c|c|c|c|c|}
\hline \multirow{2}{*}{$\begin{array}{l}\text { Variáveis } \\
(\log )\end{array}$} & \multirow[b]{2}{*}{ Lags } & \multicolumn{3}{|c|}{ Qui-quadrado } \\
\hline & & Nivel & $\begin{array}{l}1^{a} \\
\text { diferença }\end{array}$ & Defasagem \\
\hline \multirow{2}{*}{$D C$} & \multirow{2}{*}{$0-1$} & $107.14^{\text {*** }}$ & & \\
\hline & & $(0.000)$ & & \\
\hline \multirow{2}{*}{ RMD } & \multirow{2}{*}{$0-1$} & $71.51 *$ & & \\
\hline & & $(0.056)$ & & \\
\hline \multirow{2}{*}{ TS } & \multirow{2}{*}{$0-1$} & $87.15^{* * *}$ & & \\
\hline & & $(0.003)$ & & \\
\hline \multirow{2}{*}{ POP } & \multirow{2}{*}{$0-1$} & 20.35 & $275.91^{* * *}$ & \\
\hline & & $(1.000)$ & $(0.000)$ & \\
\hline \multirow{2}{*}{ TC } & \multirow{2}{*}{$0-1$} & $91.96 * * *$ & & \\
\hline & & $(0.001)$ & & \\
\hline \multirow{2}{*}{ SFIS } & \multirow{2}{*}{$0-1$} & $82.22^{* * *}$ & & \\
\hline & & $(0.008)$ & & \\
\hline \multirow{2}{*}{$\mathrm{IHH}$} & \multirow{2}{*}{$0-1$} & 65.59 & $191.47^{* * *}$ & $68.66^{*}$ \\
\hline & & $(0.130)$ & $(0.000)$ & $(0.000)$ \\
\hline \multirow{2}{*}{ IV } & \multirow{2}{*}{$0-1$} & 65.54 & $192.72^{* * *}$ & \\
\hline & & $(0.135)$ & $(0.000)$ & \\
\hline \multirow{2}{*}{ MI } & \multirow{2}{*}{$0-1$} & $201.86^{* * *}$ & & \\
\hline & & $(0.000)$ & & \\
\hline \multirow{2}{*}{ DEP } & \multirow{2}{*}{$0-1$} & 41.75 & $278.10^{* * *}$ & \\
\hline & & $(0.888)$ & $(0.000)$ & \\
\hline \multirow{2}{*}{ TE } & \multirow{2}{*}{$0-1$} & 21.87 & $255.48^{* * *}$ & \\
\hline & & $(1.000)$ & $(0.000)$ & \\
\hline \multirow{2}{*}{ ESC } & \multirow{2}{*}{$0-1$} & $74.78^{* *}$ & & \\
\hline & & $(0.032)$ & & \\
\hline \multirow{2}{*}{ GINI } & \multirow{2}{*}{$0-1$} & 60.82 & $259.71^{* * *}$ & \\
\hline & & $(0.244)$ & $(0.000)$ & \\
\hline
\end{tabular}

Fonte: Elaboração própria com base em testes realizados no Software Eviews. Notas: 1. Especificação no Eviews: Lag Lenght: Akaike Info Criterion; Kernel: Bartlett; Seleção de Bandwidth: Newey-West; 2. *, ** e ${ }^{* * *}$ rejeição de $\mathrm{H} 0$ aos níveis de significância de 10\%, de 5\% e de 1\%, respectivamente. 3. H0 (ADF-Fisher): variável apresenta uma raiz unitária (assume uma 
Daniel Azevedo Pansani, et al. Análise de Evidências e Causas do Efeito Flypaper e da Ilusão Fisca...

raiz unitária individual). Siglas: DC: despesas correntes per capita; RMD: renda mediana; TS: tax share; POP: população; TC: transferências intergovernamentais per capita; SFIS: simplicidade fiscal; IHH: índice de Herfindahl-Hirschman de concentração da receita; IV: índice de visibilidade tributária; MI: mortalidade infantil; DEP: taxa de dependência; TE: taxa de envelhecimento; ESC: taxa de atendimento escolar; GINI: índice Gini de desigualdade. Importar tabla

\section{BY-NC-ND}

